Article Type: Clinical Article

\title{
Prediction of gestational diabetes mellitus in the Born in Guangzhou Cohort Study, China
}

Kimberly K. Schaefer ${ }^{1,2, a}$, Wanqing Xiao ${ }^{1,3,4, a}$, Qiaozhu Chen ${ }^{4, a}$, Jianrong He ${ }^{1,3}$, Jinhua Lu 1,3 , Fanfan Chan ${ }^{1,3}$, Niannian Chen ${ }^{1,3}$, Mingyang Yuan ${ }^{1,3}$, Huimin Xia ${ }^{1,5}$, Kin Bong Hubert Lam $^{2}$, Jane E. Hirst ${ }^{6, *}$, Xiu Qiu ${ }^{1,3,4,{ }^{*}}$

${ }^{1}$ Division of Birth Cohort Study, Guangzhou Women and Children's Medical Center, Guangzhou Medical University, Guangzhou, China

${ }^{2}$ Nuffield Department of Population Health, University of Oxford, Oxford, UK

${ }^{3}$ Department of Woman and Child Health Care, Guangzhou Women and Children's Medical Center, Guangzhou Medical University, Guangzhou, China

${ }^{4}$ Department of Obstetrics and Gynecology, Guangzhou Women and Children's Medical Center, Guangzhou Medical University, Guangzhou, China

${ }^{5}$ Department of Neonatal Surgery, Guangzhou Women and Children's Medical Center, Guangzhou Medical University, Guangzhou, China

${ }^{6}$ Nuffield Department of Women's and Reproductive Health, University of Oxford, Oxford, UK

This article has been accepted for publication and undergone full peer review but has not been through the copyediting, typesetting, pagination and proofreading process, which may lead to differences between this version and the Version of Record. Please cite this article as doi: 10.1002/ijgo.12627

This article is protected by copyright. All rights reserved. 
${ }^{*}$ Correspondence:

Jane E. Hirst

Nuffield Department of Women's and Reproductive Health, Level 3, Women's Centre, John Radcliffe Hospital, Headley Way, Oxford, OX3 9DU, United Kingdom.

E-mail: jane.hirst@wrh.ox.ac.uk

Xiu Qiu

Division of Birth Cohort Study, Department of Woman and Child Health Care and

Department of Obstetrics and Gynecology, Guangzhou Women and Children's Medical Center, Guangzhou Medical University, 9 Jinsui Rd., Zhujiang Newtown, Tianhe District, Guangzhou 510623, China.

E-mail: qxiu0161@163.com; xiu.qiu@bigcs.org

${ }^{a}$ These authors contributed equally.

Keywords: Cohort study; Gestational diabetes mellitus; Oral glucose tolerance testing; Prediction; Risk factor; Screening.

Synopsis: Use of a risk-factor-based screening tool for gestational diabetes mellitus could reduce the number of pregnant women undergoing oral glucose tolerance testing by $25 \%$.

This article is protected by copyright. All rights reserved. 


\section{ABSTRACT}

Objective: To assess potential risk factors in identifying women at risk for gestational diabetes mellitus (GDM).

Methods: The present study included data collected as part of a prospective cohort study, and included women with singleton pregnancies who underwent initial prenatal examination at a tertiary women and children's hospital in Guangzhou, China between February 1, 2012, and December 31, 2015. Maternal characteristics and medical history were investigated to evaluate associations with GDM. A risk factor scoring system for the prediction of GDM was generated using logistic regression.

Results: Overall, 1129 (13.5\%) of 8381 women were diagnosed with GDM. Women older than 35 years had a 3.95-fold increased risk of GDM (95\% confidence interval 2.80-5.58) compared with women aged 16-25 years; obese women had a 6.54-fold higher risk (95\% confidence interval 3.50-12.23) compared with underweight women. A risk scoring system was established based on age, body mass index, family history of diabetes, weight gain, and history of GDM. Screening for women with a score of 12 or more would have reduced the number undergoing oral glucose tolerance testing by 2131 (25.4\%) patients with a sensitivity of $87 \%$ for GDM detection.

Conclusion: The assessment of risk factors for GDM could provide a foundation for improving risk-based screening strategies in this and similar populations. 


\section{INTRODUCTION}

Gestational diabetes mellitus (GDM) is a form of glucose intolerance that first occurs or is first recognized during pregnancy, and the estimated prevalence of GDM ranges from less than $1 \%$ to $28 \%$ [1]. This variation arises from different degrees of glucose intolerance among the populations studied and from inconsistencies in screening methods and diagnostic criteria [2].

The International Association of the Diabetes and Pregnancy Study Group (IADPSG) [3] has recommended universal screening for GDM. WHO adopted these guidelines in 2013 [4]; however, the expert committee acknowledged that such screening is not always feasible, particularly in resource-limited contexts.

In China, rapid urbanization and economic growth have had unprecedented effects on the health of individuals, including a rise in the proportion of adults with noncommunicable diseases such as diabetes [5] and an increase in the prevalence of obesity [6]. The rapid development in China has been accompanied by growing economic inequalities [7], and the large population makes any universal project very resource-intensive. A better understanding of the risk factors associated with GDM may therefore enable selective risk-factor-based screening that can decrease the burden on hospital resources while maximizing the chances of diagnosing GDM for early treatment and glucose management.

Many factors have been found to increase the risk of GDM, including non-white ethnicity, higher body mass index (BMI, calculated as weight in kilograms divided by the square of height in meters), older age, physical inactivity, polycystic ovary This article is protected by copyright. All rights reserved. 
syndrome, high blood pressure, family history of diabetes, and history of GDM or delivery of a macrosomic infant during previous pregnancies. However, the relative importance and interaction of risk factors can differ between Asian women and other racial or ethnic groups [8-10]. Identifying the most important factors predicting GDM at a population level could aid in the primary prevention of GDM, highlighting major modifiable risk factors that are locally relevant.

The aim of the present study was to identify risk factors for GDM and assess the predictive capabilities of these risk factors in the contemporary Chinese urban population from the Born in Guangzhou Cohort Study.

\section{MATERIALS AND METHODS}

The data used in the present secondary analysis study were collected as part of the Born in Guangzhou Cohort Study [11], a prospective cohort study conducted at Guangzhou Women and Children's Medical Center, which is a tertiary women and children's hospital in Guangzhou, China; the details have been described previously [11]. Eligible participants for the present analysis were women with a singleton pregnancy who had an initial prenatal examination between February 1, 2012, and December 31, 2015. Women were excluded if they had already had diabetes prior to the pregnancy, had completed the initial clinic visit before 14 weeks of pregnancy or after 20 weeks of pregnancy, had their oral glucose tolerance test (OGTT) outside of the time frame specified below, or had missing or abnormal values for the glucose level or other covariates. Written consent was obtained at recruitment. The study protocol was approved by the Institutional Ethics Approval Board of Guangzhou Women and Children's Medical Center.

This article is protected by copyright. All rights reserved. 
Information on maternal age, pre-pregnancy weight, height, family history of diabetes, parity, history of chronic hypertension, history of GDM and macrosomia during previous pregnancies, family income, and maternal education level were extracted from the questionnaire at recruitment. The BMI was calculated and patients were classified using the categories recommended by WHO: underweight (<18.5), normal weight (18.5-24.9), overweight (25.0-29.9), and obese $(\geq 30.0)$. The weight gain during early pregnancy was calculated as the difference between the measured weight at a 14-20-week prenatal visit and self-reported pre-pregnancy weight; it was categorized using the 2009 Institute of Medicine guidelines for weight gain during pregnancy [12]. The pregnancy duration was determined by ultrasonography examination during the first trimester.

The primary outcome for the present study was a diagnosis of GDM made on the basis of a 75-g OGTT and using the IADPSG criteria [3]. According to the IADPSG, at least one of the following criteria needs to be fulfilled for a GDM diagnosis: fasting plasma glucose, $5.1 \mathrm{mmol} / \mathrm{L}$ or more; 1 -hour glucose level, $10.0 \mathrm{mmol} / \mathrm{L}$ or more; or 2-hour glucose level, $8.5 \mathrm{mmol} / \mathrm{L}$ or more. The OGTTs were performed at 24-28 weeks of pregnancy. Blood samples were drawn before (fasting), 1 hour after, and 2 hours after the 75-g glucose load, and were collected in NaF/EDTA tubes, and analyzed using an AU5800 automatic analyzer (Beckman Coulter, Brea, CA, USA).

In the statistical analysis, the $x^{2}$ test (categorical covariates) and the two-sample $t$ test (continuous covariates) were used to determine significant differences between the GDM group and the non-GDM group. Univariate analysis was performed using unadjusted logistic regression to assess the association of each potential risk factor This article is protected by copyright. All rights reserved. 
with GDM. Variables with significant univariate associations with GDM were used in building the multivariate model by step-wise addition of covariates and a likelihood ratio test. Variables with a significant contribution by the likelihood ratio test were maintained in the multivariate model. For all analyses, an a priori adjustment was made for the pregnancy duration at the time of OGTT testing by including this variable as a covariate. The glucose levels as binary outcomes for each OGTT time point were analyzed by logistic regression.

To assess the usefulness of risk factors to predict GDM, a risk-factor-based scoring system was developed. For each factor, a weight was obtained by multiplying the $\beta$ coefficient from the multivariate logistic regression model by 10 and then rounding it to the nearest integer [13]. The risk score for each participant was then calculated by multiplying the weight and the value for each factor and adding up the individual scores to obtain the total score. The performance of this scoring system for the prediction of GDM was evaluated by calculating the sensitivity, specificity, and positive and negative predictive values and their 95\% confidence intervals $(\mathrm{Cls})$ at different risk score cutoffs. The area under the receiver operating characteristic curve (AUC) was used to evaluate the discriminative performance of the model. A literature review identified six previously published prognostic models [14-19]. These were applied to the present cohort, and the performances and scoring systems of the published and present models were then compared. Logistic recalibration was used to achieve a fair comparison of the published models [20].

This article is protected by copyright. All rights reserved. 
The performance of the scoring system was further examined using the INTERGROWTH-21st standards for weight gain during pregnancy [21]. A validation analysis of the present model was performed using data from participants enrolled between January 1 and June 30, 2016, with the same inclusion and exclusion criteria.

All analyses were performed using SAS version 9.3 (SAS Institute, Cary, NC, USA) and $R$ version 3.2.4 (R Foundation for Statistical Computing, Vienna, Austria). $P<0.05$ was considered statistically significant.

\section{RESULTS}

Initially, 13066 women with singleton pregnancies were enrolled during the study period. After exclusions (25 women with pre-existing diabetes, 2918 women with OGTT testing performed outside of the specified time frame, 1118 women with an initial clinic visit outside of the specified pregnancy duration, and 624 women with missing or abnormal values for the glucose level or other covariates), 8381 women were included in the final analysis (Figure S1). The validation analysis included 1558 women.

In total, 1129 (13.5\%) women had GDM according to the IADPSG criteria. At baseline, the mean age of the participants was $29.0 \pm 3.3$ years; the women were generally lean with a mean pre-pregnancy BMI of $20.3 \pm 2.6$, and the majority (94.6\%) had a pre-pregnancy BMI of less than 25 (Table 1 and Table S1).

This article is protected by copyright. All rights reserved. 
The strongest associations with GDM were observed for increasing age and prepregnancy BMI (Table 2). When compared with women aged 25 years or younger, there was an approximately $30 \%$ increase in the odds of GDM among women aged 26-30 years. The odds more than doubled among those aged 31-35 years and nearly quadrupled in those aged over 35 years. A similar trend was demonstrated for increasing BMI before pregnancy. Compared with women with a pre-pregnancy BMI below 18.5, the odds of a GDM diagnosis was increased in those with a higher BMI, with obese women being at the greatest risk. Women with a history of GDM in a previous pregnancy had increased odds of a GDM diagnosis when compared with multiparous women without a history of GDM. Excessive weight gain and family history of diabetes were also associated with increased odds of GDM (Table 2).

Associations between the identified risk factors and a diagnosis of GDM, stratified by each OGTT time point, are summarized in Table 3. These associations were similar in direction to the overall GDM risks but varied in magnitude across the three OGTT measures. The strongest predictor of a raised fasting plasma glucose level was the pre-pregnancy BMI. Compared with women with a pre-pregnancy BMI of less than 18.5, overweight women had eight-fold increased odds and obese women had 15 times the odds of developing GDM. Excessive weight gain was also more strongly associated with a high fasting plasma glucose level than with other OGTT values. Maternal age was the strongest predictor of an abnormal 2-hour glucose level, with women aged over 35 years having nearly eight times the odds of an abnormal 2hour glucose level compared with those aged 25 years or younger. A history of GDM was more strongly associated with an abnormal 1-hour glucose level than with other 
OGTT values. An analysis of associations between risk factors and glucose levels when assessed as continuous outcomes showed similar results (Table S2).

In the next step, six previously published prognostic models for GDM were applied to the study cohort; these models were based on maternal age, weight or BMI, family history of diabetes, and history of GDM. Three of the six models showed good calibration (Figure 1).

The present scoring system was developed based on the same variables; weight gain during pregnancy was added owing to this variable also being a significant risk factor for a GDM diagnosis (Table 2). The prevalence of GDM increased with rising risk scores, from $7.0 \%$ among women with a score of less than 10 to $47.1 \%$ among those with a score of 30 or more. If this scoring system had been used as the primary screening tool, screening for women with a score of 12 or more would have reduced the number of women undergoing an OGTT by $25.4 \%$, with a sensitivity of $86.5 \%$ and a specificity of $27.3 \%$ for the detection of GDM (Table 4 ).

The performance of the present scoring system in comparison with the performances of three of the six published prognostic models with clinical scoring of risk factors is shown in Figure 2. The AUC in the present derivation cohort was $0.639(95 \% \mathrm{Cl}$ 0.621-0.656), which was significantly higher than the AUCs derived for the three published scoring models when applied to the present cohort $(P<0.001)$. When examining the performance of this scoring system using another standard for the classification of weight gain during pregnancy, no significant difference was found in 
the performances regardless of whether the 2009 Institute of Medicine guidelines or the INTERGROWTH-21st standards were used (Table S3, Figure S2).

In the validation cohort, applying a score of 12 or more identified $84.3 \%$ of the women who developed GDM, with a specificity of $31.0 \%$. The AUC in the validation cohort was 0.649 (95\% Cl 0.605-0.692).

\section{DISCUSSION}

The strongest predictors of GDM in the present Chinese urban population were advanced maternal age, increased pre-pregnancy BMI, family history of diabetes, excessive weight gain during pregnancy, and history of GDM. The scoring system developed on the basis of these risk factors had a moderate discriminative performance for the prediction of GDM development. Of note, the scoring system performed better than three previously published scoring models that used similar risk predictors. Additionally, the present model included weight gain during pregnancy as a potentially modifiable risk factor, which has rarely been considered in previous prognostic models. The present results also indicated that different risk factors were associated with different patterns of glucose handling anomalies. To determine the relevance of this scoring system for clinical practice and the management of glycemic control in women with GDM during pregnancy, the correlation with pregnancy and longer-term outcomes should be evaluated.

A strength of the present study was the large sample of women from a contemporary urban population. Detailed questionnaires with minimal missing values and universal screening for GDM in accordance with the IADPSG guidelines enabled a robust This article is protected by copyright. All rights reserved. 
analysis. There were several limitations of the present study. First, the single-hospital sample may be not representative of all Chinese populations; however, the similarities in genetic constitution, anthropometry including BMI [22], and life styles among Southeast Asian populations imply that the present results could be generalizable to other similar populations. Second, potential bias from the selfreported pre-pregnancy weight and height used to calculate the BMI is acknowledged because women who are overweight tend to underreport their weight [23]. Given that this self-reported value was also used in calculating the weight gain during pregnancy, women who underestimated their pre-pregnancy weight would have displayed a larger weight gain; this could have falsely increased the association between weight gain and GDM. However, in practice it is rarely possible to obtain an accurate measurement of pre-pregnancy weight in pregnancy research. Finally, there could be some residual confounding in the present study because the analysis did not include information on the history of polycystic ovary syndrome and physical activities during early pregnancy.

In the present study, important novel findings are reported for a risk factor scoring system for identifying women most at risk of GDM in a Chinese population. Though the present cohort displays risk factors similar to those identified previously [20], the relationship of these risks to GDM among a southern Chinese population in a quickly developing urban region has not been widely studied; the demographics of the present population, including the low mean BMI, reinforce the need for populationspecific approaches to assessing and treating GDM. The high percentage of GDM diagnoses captured by these risk factors and the similarities in the receiver operating characteristic curves between the validation and derivation cohorts are promising This article is protected by copyright. All rights reserved. 
indicators of the capabilities of such a screening approach. Application of a GDM risk score of 12 or more, which demonstrated a sensitivity of $87 \%$ and a specificity of $27 \%$, in the present population would have resulted in approximately $25 \%$ fewer women undergoing an OGTT, which could have economic and efficiency benefits. Balanced against this advantage are the risks of missing $13 \%$ of GDM diagnoses, and of these women and their infants potentially experiencing adverse events secondary to GDM. Selective screening helps to reduce the burden of tests administered and to save medical resources, which is particularly important in resource-limited settings. In the USA, women with increasing degrees of some risk factors, such as obesity, experience more diabetes-associated adverse events [24]. Further investigation into the outcomes for the $13 \%$ of women with a relatively low risk score who would have been "missed" by selective screening would help to evaluate whether this represents a group of women with a milder phenotype of GDM.

To prevent GDM, potentially modifiable risk factors in pregnancy ideally need to be identified and assessed to determine whether the association is causal. In the present study, weight gain during pregnancy was identified as such a potentially modifiable factor. Although excessive weight gain during pregnancy has previously been associated with the risk of GDM [25], the present study provided—to our knowledge-the first quantification using an internationally valid standard. Women with excessive weight gain by $14-20$ weeks of pregnancy had increased odds of a GDM diagnosis. Excessive early weight gain was associated with a $50 \%$ and $40 \%$ increase in the odds of GDM diagnosis when compared with inadequate and expected early weight gain, respectively. To determine whether this association is causal, further work is needed to explore this risk factor in more depth.

This article is protected by copyright. All rights reserved. 
In conclusion, GDM is a common adverse event of pregnancy in Guangzhou, affecting one in eight pregnant women in the present study. Here, a simple and stable risk-factor-based screening strategy is presented that could easily be implemented and, with improvement, be applied in clinical practice to targeted OGTT testing. Further correlation with clinical outcomes during and after pregnancy is needed to understand the health and economic impact that a risk-based screening approach would have in this and similar populations.

\section{Author contributions}

KKS contributed to data analysis, and writing and revising the manuscript. WX and QC contributed to data collection and analysis, and writing and revising the manuscript. JH, JL, FC, NC, and MY contributed to data collection and revising the manuscript. $\mathrm{HX}$ and KBHL contributed to data interpretation and revising the manuscript. JEH and XQ contributed to the conception and design of the study, data interpretation, and revising the manuscript.

\section{Acknowledgments}

The Born in Guangzhou Cohort Study was supported by the National Natural Science Foundation of China (81673181), the Guangzhou Science Technology and Innovation Commission (201508030037), and the Guangdong Provincial Department of Science and Technology (2014A020213022).

\section{Conflicts of interest}

The authors have no conflicts of interest.

This article is protected by copyright. All rights reserved. 


\section{References}

[1] Jiwani A, Marseille E, Lohse N, Damm P, Hod M, Kahn JG. Gestational diabetes mellitus: results from a survey of country prevalence and practices. J Matern Fetal Neonatal Med. 2012;25(6):600-610.

[2] Hunt KJ, Schuller KL. The Increasing Prevalence of Diabetes in Pregnancy. Obstet Gynecol Clin North Am. 2007;34(2):173-199.

[3] Metzger BE, Gabbe SG, Persson B, et al. International Association of Diabetes and Pregnancy Study Groups Recommendations on the Diagnosis and Classification of Hyperglycemia in Pregnancy. Diabetes Care. 2010;33:676-682.

[4] World Health Organization. Diagnostic Criteria and Classification of Hyperglycaemia First Detected in Pregnancy. World Heal Organ. 2013:1-63.

[5] Gao WG, Dong YH, Pang ZC, et al. Qingdao 2006 Diabetes Survey Group. Increasing trend in the prevalence of Type 2 diabetes and pre-diabetes in the Chinese rural and urban population in Qingdao, China. Diabet Med. 2009;26(12):1220-1227.

[6] Mi Y-J, Zhang B, Wang H-J, et al. Prevalence and Secular Trends in Obesity Among Chinese Adults, 1991-2011. Am J Prev Med. 2015;49:661-669.

[7] Xie Y, Zhou X. Income inequality in today's China. Proc Natl Acad Sci. 2014;111:6928-6933.

[8] Kim C. Gestational diabetes mellitus in korean women: similarities and differences from other racial/ethnic groups. Diabetes Metab J. 2014;38(1):1-12.

[9] Oteng-Ntim E, Kopeika J, Seed P, Wandiembe S, Doyle P. Impact of Obesity on Pregnancy Outcome in Different Ethnic Groups: Calculating Population Attributable Fractions. PLoS One. 2013;8:e53749.

This article is protected by copyright. All rights reserved. 
[10] Hedderson M, Ehrlich S, Sridhar S, Darbinian J, Moore S, Ferrara A. Racial/Ethnic Disparities in the Prevalence of Gestational Diabetes Mellitus by BMI. Diabetes Care. 2012;35:1492-1498.

[11] Qiu X, Lu J-H, He J-R, et al. The Born in Guangzhou Cohort Study (BIGCS). Eur J Epidemiol. 2017:1-10.

[12] K.M. Rasmussen, A.L.Yaktine. Weight Gain During Pregnancy: Reexamining the Guidelines. Washington (DC): National Academies Press (US); 2009.

[13] Zhou X, Qiao Q, Ji L, et al. Nonlaboratory-based risk assessment algorithm for undiagnosed type 2 diabetes developed on a nation-wide diabetes survey. Diabetes Care. 2013;36(12):3944-3952.

[14] Naylor CD, Sermer M, Chen E, Farine D. Selective screening for gestational diabetes mellitus. N Engl J Med. 1997;337:1591-1596.

[15] Shirazian N, Emdadi R, Mahboubi M, et al. Screening for gestational diabetes: usefulness of clinical risk factors. Arch Gynecol Obstet. 2009;280:933-937. [16] Tran TS, Hirst JE, Do MA, Morris JM, Jeffery HE. Early prediction of gestational diabetes mellitus in Vietnam: clinical impact of currently recommended diagnostic criteria. Diabetes Care. 2013;36:618-624.

[17] Eleftheriades M, Papastefanou I, Lambrinoudaki I, et al. Elevated placental growth factor concentrations at 11-14 weeks of gestation to predict gestational diabetes mellitus. Metabolism. 2014;63:1419-1425.

[18] Teede HJ, Harrison CL, Teh WT, Paul E, Allan CA. Gestational diabetes: development of an early risk prediction tool to facilitate opportunities for prevention. Aust N Z J Obstet Gynaecol. 2011;51(6):499-504.

This article is protected by copyright. All rights reserved. 
[19] van Leeuwen M, Opmeer BC, Zweers EJ, et al. Estimating the risk of gestational diabetes mellitus: a clinical prediction model based on patient characteristics and medical history. BJOG. 2010;117(1):69-75.

[20] Lamain-de Ruiter M, Kwee A, Naaktgeboren CA, et al. External validation of prognostic models to predict risk of gestational diabetes mellitus in one Dutch cohort: prospective multicentre cohort study. BMJ. 2016;30;354:i4338.

[21] Cheikh Ismail L, Bishop DC, Pang R, et al. Gestational weight gain standards based on women enrolled in the Fetal Growth Longitudinal Study of the INTERGROWTH-21(st) Project: a prospective longitudinal cohort study. Br Med J. 2016;352:i555.

[22] World Health Organization. Global Database on Body Mass Index. http://apps.who.int/bmi/index.jsp. Accessed April 9, 2018.

[23] Connor Gorber S, Tremblay M, Moher D, Gorber B. A comparison of direct vs. selfreport measures for assessing height, weight and body mass index: a systematic review. Obes Rev. 2007;8:307-326.

[24] Roman, A. S., A. Rebarber, N. S. Fox, et al. The effect of maternal obesity on pregnancy outcomes in women with gestational diabetes. J Matern Fetal Neonatal Med. 2011;24(5): 723-727.

[25] Brunner S, Stecher L, Ziebarth S, et al. Excessive gestational weight gain prior to glucose screening and the risk of gestational diabetes: a meta-analysis. Diabetologia. 2015;58:2229-2237.

Figure 1 Calibration curves of published prognostic models to predict the risk of gestational diabetes mellitus in the study cohort. The ideal calibration line means an intercept of 0 and a

This article is protected by copyright. All rights reserved. 
slope of 1 for the calibration plot. Naylor et al. [14] (A); Tedee et al. [18] (B); Shirazian et al. [15] (C); Tran et al. [16] (D); van Leeuwen et al. [19] (E); Eleftheriades et al. [17] (F).

Figure 2 Receiver operating characteristic curve for risk-factor-based screening of gestational diabetes mellitus in the present study in comparison with other published clinical scoring systems.

Figure S1 Born in Guangzhou Cohort Study participants included in the current study.

Figure S2 Discriminative performances of the scoring systems using different standards for weight gain during pregnancy.

Table S1 Baseline characteristics of all participants.

Table S2 Associations between risk factors and continuous glucose levels.

Table S3 Associations between risk factors and diagnosis of gestational diabetes mellitus using the INTERGROWTH-21st standards for weight gain during pregnancy [21].

This article is protected by copyright. All rights reserved. 
Table 1 Baseline characteristics. ${ }^{a}$

\begin{tabular}{|c|c|c|c|}
\hline Characteristics & $\begin{array}{l}\text { GDM group } \\
(\mathrm{n}=1129)\end{array}$ & $\begin{array}{l}\text { Non-GDM group } \\
(n=7252)\end{array}$ & $P$ value \\
\hline Maternal age, y & $30.1 \pm 3.6$ & $28.8 \pm 3.2$ & $<0.001$ \\
\hline Categorized maternal age, y & & & $<0.001$ \\
\hline $16-25$ & $88(7.8)$ & $930(12.8)$ & \\
\hline $26-30$ & $579(51.3)$ & $4388(60.5)$ & \\
\hline $31-35$ & 376 (33.3) & 1708 (23.6) & \\
\hline $36-49$ & $86(7.6)$ & $226(3.1)$ & \\
\hline BMI before pregnancy & $21.12 \pm 2.99$ & $20.19 \pm 2.55$ & $<0.001$ \\
\hline Categorized $\mathrm{BM} \mathrm{I}^{\mathrm{b}}$ & & & $<0.001$ \\
\hline$<18.5$ & 196 (17.4) & $1957(27.0)$ & \\
\hline$\geq 18.5$ and $<25$ & $817(72.4)$ & $4961(68.4)$ & \\
\hline$\geq 25$ and $<30$ & $96(8.5)$ & $309(4.3)$ & \\
\hline$\geq 30$ & $20(1.8)$ & $25(0.3)$ & \\
\hline Family history of diabetes mellitus & $166(14.7)$ & $676(9.3)$ & $<0.001$ \\
\hline History of chronic hypertension & 0 & $4(0.1)$ & 0.430 \\
\hline $\begin{array}{l}\text { Early weight gain during pregnancy, } \\
\mathrm{kg}\end{array}$ & $3.29 \pm 3.15$ & $2.91 \pm 2.98$ & $<0.001$ \\
\hline Categorized weight gain ${ }^{c}$ & & & $<0.001$ \\
\hline Inadequate & 466 (41.3) & 3350 (46.2) & \\
\hline Adequate & $385(34.1)$ & $2620(36.1)$ & \\
\hline Excessive & $278(24.6)$ & $1282(17.7)$ & \\
\hline History of GDM & & & $<0.001$ \\
\hline Nulliparous & $1005(89.0)$ & $6480(89.4)$ & \\
\hline Multiparous without history of GDM & $108(9.6)$ & $740(10.2)$ & \\
\hline Multiparous with history of GDM & $16(1.4)$ & $32(0.4)$ & \\
\hline History of macrosomia & & & 0.843 \\
\hline Nulliparous & $1005(89.0)$ & $6480(89.4)$ & \\
\hline $\begin{array}{l}\text { Multiparous without history of } \\
\text { macrosomia }\end{array}$ & $116(10.3)$ & $713(9.8)$ & \\
\hline $\begin{array}{l}\text { Multiparous with history of } \\
\text { macrosomia }\end{array}$ & $8(0.7)$ & $59(0.8)$ & \\
\hline Fetal sex & & & 0.242 \\
\hline Male & $465(41.2)$ & 2854 (39.4) & \\
\hline Female & $664(58.8)$ & $4398(60.6)$ & \\
\hline Maternal education & & & 0.378 \\
\hline High school and below & $84(7.4)$ & $609(8.4)$ & \\
\hline Vocational/technical college & $284(25.2)$ & $1784(24.6)$ & \\
\hline Undergraduate & 631 (55.9) & $3928(54.2)$ & \\
\hline Postgraduate & $130(11.5)$ & $931(12.8)$ & \\
\hline Family income & & & 0.891 \\
\hline$\leq 4500 \mathrm{RMB}$ & $31(2.7)$ & $199(2.7)$ & \\
\hline 4501-9000 RMB & $174(15.4)$ & $1202(16.6)$ & \\
\hline $9001-35,000 \mathrm{RMB}$ & $707(62.6)$ & $4458(61.5)$ & \\
\hline$>35,000 \mathrm{RMB}$ & $184(16.3)$ & $1169(16.1)$ & \\
\hline Refused to answer & $33(2.9)$ & $224(3.1)$ & \\
\hline
\end{tabular}

Abbreviations: BMI, body mass index (calculated as weight in kilograms divided by the square of height in meters; GDM, gestational diabetes mellitus.

${ }^{a}$ Values are given as mean \pm SD or number (percentage).

${ }^{\mathrm{b}}$ WHO cutoff points used for the BMI categories.

${ }^{\mathrm{C}}$ Using the weight gain categories defined by the Institute of Medicine [12].

This article is protected by copyright. All rights reserved. 
Table 2 Association between risk factors and GDM diagnosis.

\begin{tabular}{|c|c|c|c|c|}
\hline Risk factor & OR $(95 \% \mathrm{Cl})$ & $\mathrm{aOR}(95 \% \mathrm{Cl})^{\mathrm{a}}$ & $\beta$-coefficient & Score \\
\hline \multicolumn{5}{|l|}{ Maternal age, y } \\
\hline $16-25$ & 1.00 & 1.00 & - & 0 \\
\hline $26-30$ & $1.39(1.11-1.77)$ & $1.34(1.06-1.70)$ & 0.29 & 3 \\
\hline $31-35$ & $2.33(1.83-2.99)$ & $2.23(1.73-2.87)$ & 0.80 & 8 \\
\hline $36-49$ & $4.02(2.89-5.60)$ & $3.95(2.80-5.58)$ & 1.37 & 14 \\
\hline \multicolumn{5}{|l|}{ Categorized $\mathrm{BMI}^{\mathrm{b}}$} \\
\hline$<18.5$ & 1.00 & 1.00 & & 0 \\
\hline$\geq 18.5$ and $<25$ & $1.64(1.40-1.94)$ & $1.48(1.26-1.75)$ & 0.39 & 4 \\
\hline$\geq 25$ and $<30$ & $3.10(2.36-4.07)$ & $2.60(1.96-3.43)$ & 0.95 & 10 \\
\hline$\geq 30$ & $8.00(4.36-14.66)$ & $6.54(3.50-12.23)$ & 1.88 & 19 \\
\hline \multicolumn{5}{|l|}{$\begin{array}{l}\text { Family history of diabetes } \\
\text { mellitus }\end{array}$} \\
\hline No & 1.00 & 1.00 & - & 0 \\
\hline Yes & $1.68(1.40-2.01)$ & $1.51(1.25-1.82)$ & 0.41 & 4 \\
\hline \multicolumn{5}{|l|}{$\begin{array}{l}\text { Weight gain during pregnancy } \\
c\end{array}$} \\
\hline Inadequate & 1.00 & 1.00 & - & 0 \\
\hline Adequate & $1.06(0.91-1.22)$ & $1.06(0.91-1.23)$ & 0.06 & 1 \\
\hline Excessive & $1.56(1.33-1.83)$ & $1.49(1.26-1.76)$ & 0.40 & 4 \\
\hline \multicolumn{5}{|l|}{ History of GDM } \\
\hline $\begin{array}{l}\text { Multiparous without history of } \\
\text { GDM }\end{array}$ & 1.00 & 1.00 & - & 0 \\
\hline Nulliparous & $1.06(0.86-1.31)$ & $1.58(1.26-1.99)$ & 0.46 & 5 \\
\hline $\begin{array}{l}\text { Multiparous with history of } \\
\text { GDM }\end{array}$ & $3.43(1.82-6.45)$ & $3.20(1.67-6.13)$ & 1.16 & 12 \\
\hline
\end{tabular}

Abbreviations: aOR, adjusted odds ratio; BMl, body mass index (calculated as weight in kilograms divided by the square of height in meters); $\mathrm{Cl}$, confidence interval; GDM, gestational diabetes mellitus; OR, odds ratio.

${ }^{a}$ Adjusted for all variables in this table and the pregnancy duration at the date of oral glucose tolerance testing.

${ }^{\mathrm{b}}$ WHO cutoff points used for the BMI categories.

${ }^{c}$ Using the weight gain categories defined by the Institute of Medicine [12].

This article is protected by copyright. All rights reserved. 
Table 3 Associations between risk factors and abnormal glucose levels. ${ }^{a, b}$

\begin{tabular}{|c|c|c|c|}
\hline Risk factor & $\begin{array}{l}\text { Abnormal FPG } \\
\text { value }\end{array}$ & $\begin{array}{l}\text { Abnormal 1-hour glucose } \\
\text { value }\end{array}$ & $\begin{array}{l}\text { Abnormal 2-hour glucose } \\
\text { value }\end{array}$ \\
\hline \multicolumn{4}{|l|}{ Maternal age, y } \\
\hline $16-25$ & 1.00 & 1.00 & 1.00 \\
\hline $26-30$ & $0.89(0.58-1.37)$ & $1.20(0.90-1.61)$ & $2.07(1.45-2.96)$ \\
\hline $31-35$ & $1.67(1.06-2.61)$ & $1.97(1.44-2.68)$ & $3.58(2.47-5.17)$ \\
\hline $36-49$ & $2.42(1.31-4.46)$ & $2.93(1.92-4.50)$ & $7.95(5.09-12.41)$ \\
\hline \multicolumn{4}{|l|}{ Categorized $\mathrm{BMI}^{\mathrm{C}}$} \\
\hline$<18.5$ & 1.00 & 1.00 & 1.00 \\
\hline$\geq 18.5$ and $<25$ & $3.55(2.26-5.60)$ & $1.54(1.24-1.91)$ & $1.19(0.97-1.45)$ \\
\hline$\geq 25$ and $<30$ & $8.04(4.58-14.14)$ & $2.70(1.92-3.79)$ & $2.34(1.69-3.25)$ \\
\hline$\geq 30$ & $15.09(5.85-38.95)$ & $8.83(4.58-17.00)$ & $4.49(2.34-9.01)$ \\
\hline \multicolumn{4}{|l|}{$\begin{array}{l}\text { Family history of } \\
\text { diabetes mellitus }\end{array}$} \\
\hline No & 1.00 & 1.00 & 1.00 \\
\hline Yes & $1.48(1.05-2.09)$ & $1.69(1.35-2.11)$ & $1.80(1.45-2.24)$ \\
\hline \multicolumn{4}{|l|}{$\begin{array}{l}\text { Weight gain during } \\
\text { pregnancy }{ }^{d}\end{array}$} \\
\hline Inadequate & 1.00 & 1.00 & 1.00 \\
\hline Adequate & $1.22(0.91-1.64)$ & $1.11(0.92-1.34)$ & $0.89(0.74-1.06)$ \\
\hline Excessive & $2.00(1.48-2.71)$ & $1.68(1.37-2.05)$ & $1.06(0.86-1.30)$ \\
\hline \multicolumn{4}{|l|}{$\begin{array}{l}\text { History of } \\
\text { gestational } \\
\text { diabetes mellitus }\end{array}$} \\
\hline $\begin{array}{l}\text { Multiparous } \\
\text { without history of } \\
\text { GDM }\end{array}$ & 1.00 & 1.00 & 1.00 \\
\hline Nulliparous & $1.64(1.06-2.53)$ & $1.73(1.29-2.32)$ & $1.48(1.13-1.94)$ \\
\hline $\begin{array}{l}\text { Multiparous with } \\
\text { history of GDM }\end{array}$ & $0.59(0.08-4.50)$ & $4.32(2.10-8.89)$ & $2.33(1.09-4.96)$ \\
\hline
\end{tabular}

Abbreviations: $\mathrm{BMI}$, body mass index (calculated as weight in kilograms divided by the square of height in meters); $\mathrm{Cl}$, confidence interval; FPG, fasting plasma glucose; OR, odds ratio.

${ }^{a}$ Values are given as adjusted odds ratio (95\% confidence interval). The odds ratios were adjusted for all variables in this table and the pregnancy duration at the date of oral glucose tolerance testing.

${ }^{\mathrm{b}}$ Abnormal FPG value: $\geq 5.1 \mathrm{mmol} / \mathrm{L}$; abnormal 1 -hour glucose value: $\geq 10.0 \mathrm{mmol} / \mathrm{L}$; abnormal 2-hour glucose value: $\geq 8.5 \mathrm{mmol} / \mathrm{L}$.

${ }^{c}$ WHO cutoff points used for the BMI categories.

${ }^{d}$ Using the weight gain categories defined by the Institute of Medicine [12].

This article is protected by copyright. All rights reserved. 
Table 4 Performance of the risk factor scoring system for the prediction of gestational diabetes mellitus at selected cutoff values $(n=8381)$.

\begin{tabular}{|c|c|c|c|c|c|}
\hline $\begin{array}{l}\text { Cutoff } \\
\text { value of } \\
\text { risk score }\end{array}$ & $\begin{array}{l}\text { No. of patients } \\
\text { who would } \\
\text { undergo OGTT }\end{array}$ & $\begin{array}{l}\text { Sensitivity } \\
(95 \% \text { Cl), \% }\end{array}$ & $\begin{array}{l}\text { Specificity } \\
(95 \% \text { Cl), \% }\end{array}$ & $\begin{array}{l}\text { Positive } \\
\text { predictive value } \\
(95 \% \mathrm{Cl}), \%\end{array}$ & $\begin{array}{l}\text { Negative } \\
\text { predictive value } \\
(95 \% \mathrm{Cl}), \%\end{array}$ \\
\hline 9 & $7259(86.6)$ & $\begin{array}{l}92.8(91.3- \\
94.3)\end{array}$ & $\begin{array}{l}14.4(13.6- \\
15.2)\end{array}$ & $14.4(13.6-15.3)$ & $92.8(91.3-94.3)$ \\
\hline 10 & $6480(77.3)$ & $\begin{array}{l}88.2(86.3- \\
90.1)\end{array}$ & $\begin{array}{l}24.4(23.4- \\
25.4)\end{array}$ & $15.4(14.5-16.3)$ & $93.0(91.9-94.2)$ \\
\hline 11 & $6290(75.1)$ & $\begin{array}{l}87.0(85.0- \\
88.9)\end{array}$ & $\begin{array}{l}26.8(25.8- \\
27.8)\end{array}$ & $15.6(14.7-16.5)$ & $93.0(91.9-94.1)$ \\
\hline 12 & $6250(74.6)$ & $\begin{array}{l}86.5(84.6- \\
88.5)\end{array}$ & $\begin{array}{l}27.3(26.3- \\
28.3)\end{array}$ & $15.6(14.7-16.5)$ & $92.9(91.8-94.0)$ \\
\hline 13 & $4616(55.1)$ & $\begin{array}{l}71.2(68.6- \\
73.9)\end{array}$ & $\begin{array}{l}47.4(46.3- \\
48.6)\end{array}$ & $17.4(16.3-18.5)$ & $91.4(90.5-92.3)$ \\
\hline 14 & $3108(37.1)$ & $\begin{array}{l}54.5(51.6- \\
57.4)\end{array}$ & $\begin{array}{l}65.6(64.5- \\
66.7)\end{array}$ & $19.8(18.4-21.2)$ & $90.3(89.5-91.1)$ \\
\hline 15 & 2981 (35.6) & $\begin{array}{l}52.9(50.0- \\
55.8)\end{array}$ & $\begin{array}{l}67.1(66.0- \\
68.2)\end{array}$ & $20.0(18.6-21.4)$ & $90.1(89.4-90.9)$ \\
\hline
\end{tabular}

Abbreviations: $\mathrm{Cl}$, confidence interval; OGTT, oral glucose tolerance test.

${ }^{a}$ Values are given as number (percentage).

This article is protected by copyright. All rights reserved. 
A

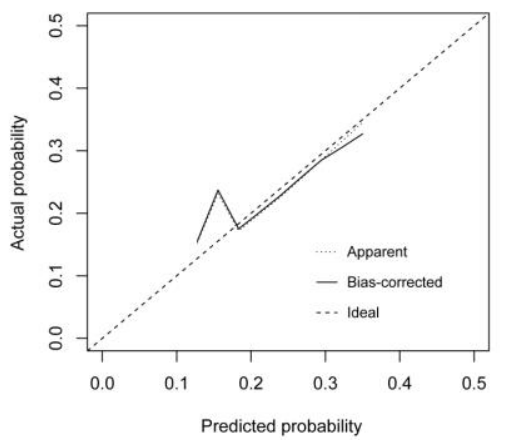

c
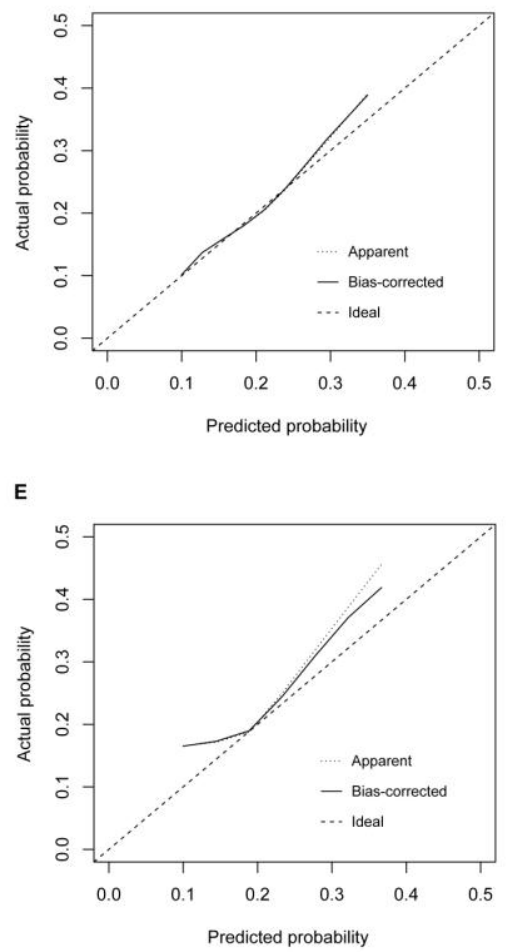

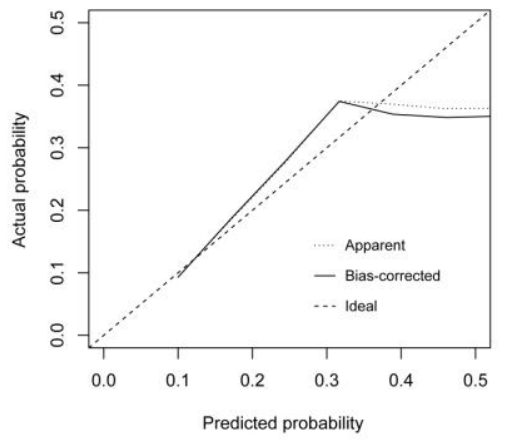

D
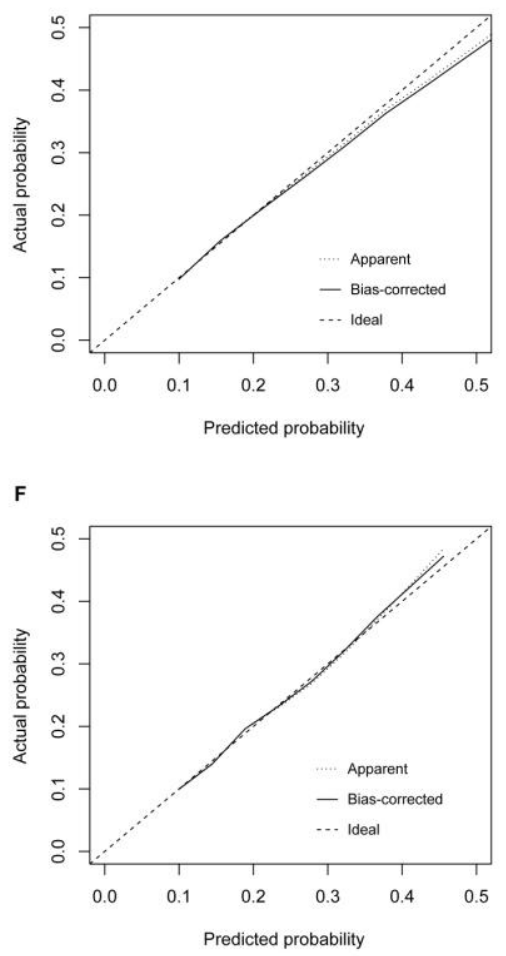

This article is protected by copyright. All rights reserved. 


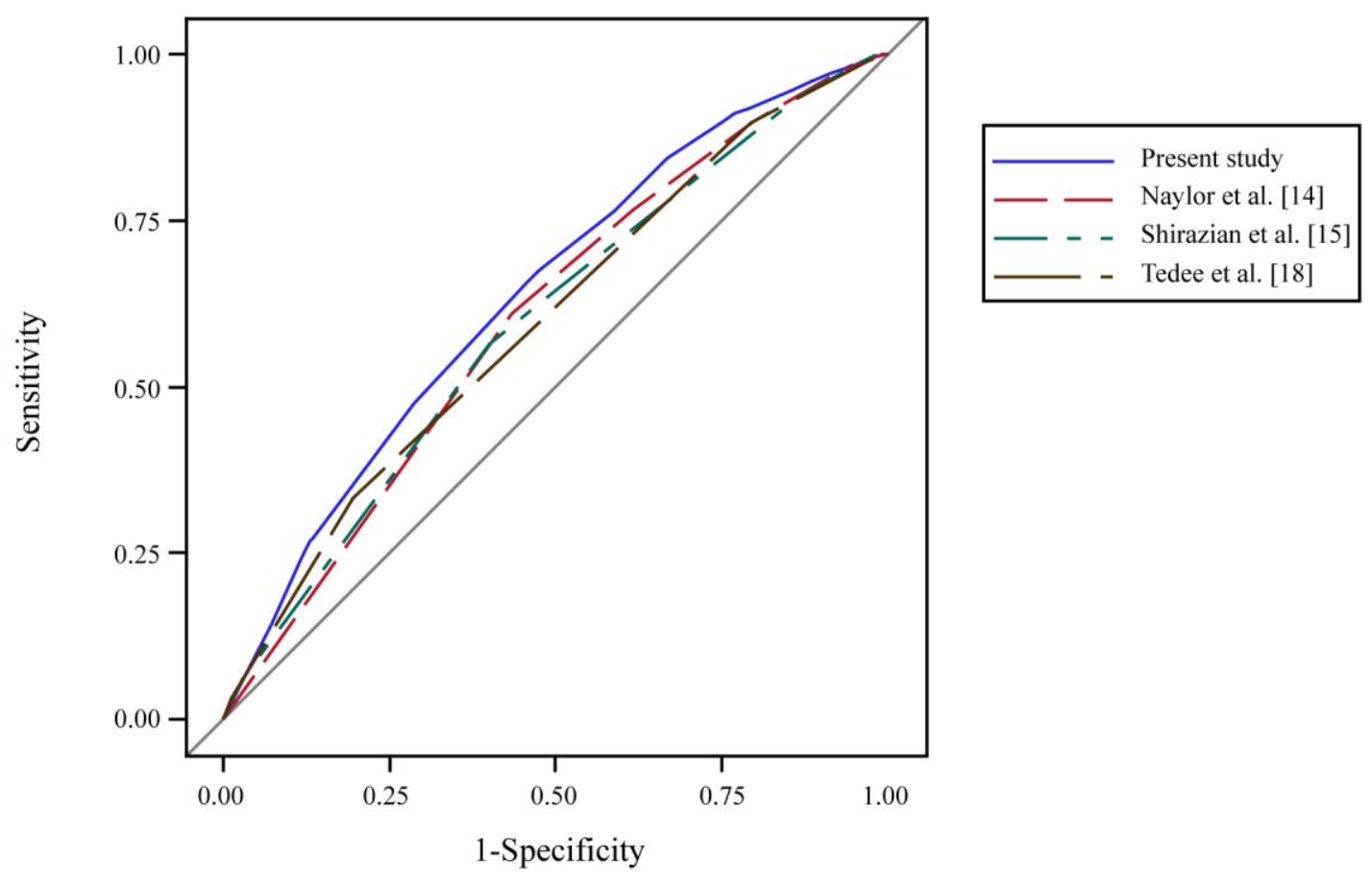

This article is protected by copyright. All rights reserved. 